Original Article

\title{
Comparison of the Restoration of Breast Feeding after Percutaneous Aspiration vs Incision and Drainage for Management of Breast Abscess
}

\author{
Noor Hussain, Imran Khan, Tanweer Ahmed, Sughra Parveen, \\ Mariam Malik, Muhammad Iqbal Khan
}

ABSTRACT

BACKGROUND: Mastitis is not uncommon among lactating woman. This is caused by local inflammation and/or infection of terminal lactiferous ducts. Incision and drainage followed by postoperative antibiotics is the treatment of choice for such abscesses depending on culture and sensitivity. Ultrasound guided needle aspiration is also effective for breast abscesses.

OBJECTIVE: To compare the outcome of percutaneous aspiration with incision drainage for management of breast abscess among lactating mothers.

METHODOLOGY: This comparative study was carried out at Jinnah Postgraduate Medical Centre, Karachi, Pakistan from August 2015 to August 2016. A total of 90 women with breast abscess were included according to inclusion and exclusion criteria. These women were randomly allocated into two groups. Forty-five in group A, treated with percutaneous aspiration, and 45 patients in group B treated with incision and drainage for breast abscess. Percutaneous aspiration was done after radiological estimation of size, site and shape. After the intervention, all the patients were observed for the outcome parameter i.e. early restoration of breast feeding, as if the mother starts feeding the baby within 24 hours after the procedure All the information was collected on a specially designed Performa.

RESULTS: Rate of early restoration of breast feeding was significantly high in group A (percutaneous aspiration) as compared to group B (drainage for breast abscess) [82.2\% vs. $57.8 \%$ ); 0.011$]$.

CONCLUSION: We conclude that percutaneous aspiration of breast abscess is a minimally invasive, simple outpatient procedure without the need of general anesthesia with superior cosmetic results and high satisfaction rate.

KEY WORDS: Mastitis, Percutaneous aspiration, Lactating mothers, Breast abscess

This article may be cited as: Hussain N, Khan I, Ahmed T, Parveen S, Malik M, Khan MI. Comparison of the Restoration of Breast Feeding after Percutaneous Aspiration vs Incision and Drainage for Management of Breast Abscess. J Liaquat Uni Med Health Sci. 2018;17(01):47-51. doi: 10.22442/jlumhs.181710548

\section{INTRODUCTION}

Mastitis is not uncommon among lactating woman (approximately 1.5 to $9 \%$ of lactating mothers develop mastitis). This is caused by local inflammation and/or infection of terminal lactiferous ducts. Milk stasis either by ineffective suckling of the infant or by restricted feeding plays an important role in the development of mastitis ${ }^{1}$. Despite early treatment, some cases are complicated by abscess formation commonly caused by Staphylococcus and Streptococcus ${ }^{2}$. Risk factors for the development of primary as well as recurrent lactational breast abscess are obesity, smoking and mastitis $^{3,4}$. The treatment of abscess is drainage either by incision or by aspiration.

Incision and drainage followed by postoperative antibiotics is the treatment of choice for these abscesses depending on culture and sensitivity.
Unfortunately, this type of treatment can lead to postoperative complications like unsightly scar formation and had a negative effect for the suckling, resulting in giving-up of breast-feeding ${ }^{5}$.

Ultrasound-guided (USG) percutaneous needle aspiration, have been considered useful for fluid aspiration from breast cysts of less than 3 centimeters ${ }^{6}$. Ultrasound is a useful tool in diagnosis of breast abscesses and guiding needle placement during aspiration. Ultrasound also helps in visualization of multiple abscess loculation and thus useful in needle aspiration of breast abscesses. This procedure has been found useful, with less recurrence, excellent cosmetic result and has less costs $^{7}$ with cure rate of $93 \%{ }^{8}$.

Generally, breast abscess among lactating mothers are treated with incision drainage with attending 
risk of cessation of breast feeding, scaring and dissatisfaction by the patients. Percutaneous aspiration has yet not established as gold standard despite encouraging results even though percutaneous aspiration has encouraging results ${ }^{9}$. We design this study to compare the two techniques, so that a technique with better outcome with respect to continuation of breast feeding may be offered to the patients.

\section{OBJECTIVE}

To compare the outcome of percutaneous aspiration with incision drainage for management of breast abscess among lactating mothers.

\section{METHODOLOGY}

This comparative study after approval from ethical committee was carried out at Jinnah Postgraduate Medical Centre, Karachi, Pakistan from August 2015 to August 2016. Female patients presented to surgical out patient's department and emergency days allocated to our ward, between age of 20-45years, with an abscess size of equal to or less than $3 \mathrm{~cm}$ and without having co-morbid like diabetes mellitus, chronic liver disease and chronic renal failure. Patients having previous history of breast surgery and or diagnosed as breast carcinoma were excluded from the study.

After taking informed consent ninety cases fulfilling inclusion criteria were registered through Emergency Department of General Surgery, Jinnah Postgraduate Medical Centre Karachi. Patients were equally divided into two groups, 45 patients in group $A$ received percutaneous aspiration, and 45 patients in group B were treated with incision drainage for breast abscess. Demographic history [including age (in years), height (meters) weight $(\mathrm{kg})$ ] was noted. After clinical and ultrasonographical examination for estimating site, size and shape; the surgery was done by a resident surgeon who has at least 2 years experience in the field of surgery. Once intervention is done, all the patients were observed for the outcome parameters i.e. early restoration of breast feeding, as if the mother starts feeding the baby within 24 hours after the procedure (Percutaneous aspiration or Incision \& drainage).

All the collected data was entered analyzed by into SPSS $^{\circledR}$ version 10. Quantitative data like age (in years), duration of breast feeding (in hours), weight (in $\mathrm{Kg}$ ), height (in meters), BMI was presented as means and standard deviations. The two groups were compared for any statistical significance. Chi-square test was applied to compare outcome variable.
Stratification was done with regards to age, duration of breast feeding \& BMI to see the impact on outcome variable, fisher exact test or chi-square test was applied-value $\leq 0.05$ was taken as significant.

\section{RESULTS}

A total of 90 women with breast abscess were divided into two groups. Forty-five in group A, treated with percutaneous aspiration, and 45 in group $B$ treated with drainage for breast abscess. Commonly observed age was between 26 to 30 years. The average age of the women in group A and group B was $27.91 \pm 4.23$ years and $28 \quad \pm 5.04$ years respectively. Other demographic characteristics of the patients with respect to groups are shown in table I. Peripheral site of breast abscess was commonly observed in both groups, $\{n=37(82 \%)\}$ and $\{n=42(93 \%)\}$ for group $A$ and group $B$ respectively. Most of the patients required single aspiration $(n=38)$ and rest required multiple aspiration $(n=7)$.

Early restoration of breast feeding (within 24 hours) was observed more frequently in group $A$ (percutaneous aspiration) as compare to group B (drainage for breast abscess) [82.2\% vs. $57.8 \%$ ); $0.011]$. Similarly rate of breast feeding cessation was low $\{\mathrm{n}=8(17.8 \%)\}$ in percutaneous group versus $\{\mathrm{n}=19(42.2 \%)\}$ among incision drainage group as shown in table II.

Rate of early restoration of breast feeding was high in group A (about $80 \%$ ) than group B (below $80 \%$ ) in all age group but there were no statistical significant as shown in table III. With respect to BMI, rate of early restoration of breast feeding was high in group $A$ as compare to group B for those women who had BMI below and equal to $25 \mathrm{~kg} / \mathrm{m}^{2}$ while there was no significant effect in overweight $\left(25.1\right.$ to $\left.30 \mathrm{~kg} / \mathrm{m}^{2}\right)$ and obese $\left(>30 \mathrm{~kg} / \mathrm{m}^{2}\right)$ as shown in table IV.

TABLE I: DEMOGRAPHIC CHARACTERISTICS OF THE VARIABLES WITH RESPECT TO GROUPS

\begin{tabular}{|l|c|c|c|c|}
\hline & \multicolumn{2}{|c|}{ Group A $(\mathbf{n}=45)$} & \multicolumn{2}{c|}{ Group B $(\mathbf{n}=45)$} \\
\cline { 2 - 5 } & Mean & $\begin{array}{c} \pm \text { Std. } \\
\text { Deviation }\end{array}$ & Mean & $\begin{array}{c} \pm \text { Std. } \\
\text { Deviation }\end{array}$ \\
\hline Age $(\mathrm{Yrs})$ & 27.91 & 4.236 & 28 & 5.04 \\
\hline Weight $(\mathrm{Kg})$ & 71.00 & 9.181 & 68.58 & 9.86 \\
\hline Height $(\mathrm{Cm})$ & $\begin{array}{c}157.3 \\
4\end{array}$ & 8.855 & 155.47 & 3.996 \\
\hline BMl $\left(\mathrm{Kg} / \mathrm{m}^{2}\right)$ & 28.81 & 3.96 & 28.36 & 3.82 \\
\hline $\begin{array}{l}\text { Duration of Breast } \\
\text { feeding }(\mathrm{Hrs})\end{array}$ & 19.62 & 11.930 & 27.38 & 16.407 \\
\hline
\end{tabular}


Noor Hussain, Imran Khan, Tanweer Ahmed, Sughra Parveen, Mariam Malik, Muhammad Iqbal Khan

\section{TABLE II: COMPARISON OF EARLY RESTORATION OF BREAST FEEDING IN BOTH GROUPS}

\begin{tabular}{|c|c|c|c|c|}
\begin{tabular}{|c|c|c|} 
Early Restora- \\
tion of the \\
Breast Feeding
\end{tabular} & $\begin{array}{c}\text { Group A } \\
\mathbf{n = 4 5}\end{array}$ & $\begin{array}{c}\text { Group B } \\
\mathbf{n = 4 5}\end{array}$ & Total & P-Value \\
\cline { 1 - 4 } Yes & $37(82.2 \%)$ & $26(57.8 \%)$ & 63 & 0.011 \\
\cline { 1 - 4 } No & $8(17.8 \%)$ & $19(42.2 \%)$ & 27 & \\
\hline
\end{tabular}

TABLE III: COMPARISON OF EARLY RESTORATION OF BREAST FEEDING WITH RESPECT TO AGE GROUPS

\begin{tabular}{|c|c|c|c|c|}
\hline $\begin{array}{c}\text { Age } \\
\text { Groups } \\
\text { (Years) }\end{array}$ & $\begin{array}{c}\text { Early } \\
\text { restoration of } \\
\text { breast feeding }\end{array}$ & Group A & Group B & P-Value \\
\hline \multirow[t]{2}{*}{$<=25$} & $\begin{array}{l}\text { Yes } \\
\text { NO }\end{array}$ & $\begin{array}{l}9(81.8 \%) \\
2(18.2 \%)\end{array}$ & $\begin{array}{l}7(50 \%) \\
7(50 \%)\end{array}$ & \multirow[t]{2}{*}{0.21} \\
\hline & Total & 11 & 14 & \\
\hline \multirow[t]{2}{*}{26 to 30} & $\begin{array}{l}\text { Yes } \\
\text { NO }\end{array}$ & $\begin{array}{r}20 \\
(83.3 \%) \\
4(16.7 \%)\end{array}$ & $\begin{array}{r}14(70 \%) \\
6(30 \%)\end{array}$ & \multirow[t]{2}{*}{0.47} \\
\hline & Total & 24 & 20 & \\
\hline \multirow[t]{2}{*}{$>30$} & $\begin{array}{l}\text { Yes } \\
\text { NO }\end{array}$ & $\begin{array}{l}8(80 \%) \\
2(20 \%) \\
\end{array}$ & $\begin{array}{l}5(45.5 \%) \\
6(54.5 \%) \\
\end{array}$ & \multirow[t]{2}{*}{0.18} \\
\hline & Total & 10 & 11 & \\
\hline
\end{tabular}

TABLE IV:

\section{COMPARISON OF EARLY RESTORATION OF BREAST FEEDING WITH RESPECT TO BMI}

\begin{tabular}{|c|c|c|c|c|}
\hline $\begin{array}{l}\text { Body } \\
\text { Mass } \\
\text { Index }\end{array}$ & $\begin{array}{c}\text { Early } \\
\text { restoration of } \\
\text { breast feeding }\end{array}$ & Group A & Group B & $\begin{array}{c}\text { P- } \\
\text { Value }\end{array}$ \\
\hline \multirow[t]{2}{*}{$\leq 25 \mathrm{~kg} / \mathrm{m}^{2}$} & $\begin{array}{l}\text { Yes } \\
\text { No }\end{array}$ & $\begin{array}{r}8(100 \%) \\
0(0 \%)\end{array}$ & $\begin{array}{l}7(58.3 \%) \\
5(41.7 \%)\end{array}$ & \multirow[t]{2}{*}{0.035} \\
\hline & Total & 8 & 12 & \\
\hline \multirow{2}{*}{$\begin{array}{l}25.1 \text { to } 30 \\
\mathrm{~kg} / \mathrm{m}^{2}\end{array}$} & $\begin{array}{l}\text { Yes } \\
\text { No }\end{array}$ & $\begin{array}{r}16(80 \%) \\
4(20 \%)\end{array}$ & $\begin{array}{l}12(54.5 \%) \\
10(45.5 \%)\end{array}$ & \multirow[t]{2}{*}{0.11} \\
\hline & Total & 20 & 22 & \\
\hline \multirow{2}{*}{$>30 \mathrm{~kg} / \mathrm{m}^{2}$} & $\begin{array}{l}\text { Yes } \\
\text { No }\end{array}$ & $\begin{array}{r}13(76.5 \%) \\
4(23.5 \%)\end{array}$ & $\begin{array}{l}7(63.6 \%) \\
4(36.4 \%)\end{array}$ & \multirow[t]{2}{*}{0.67} \\
\hline & Total & 17 & 11 & \\
\hline
\end{tabular}

\section{DISCUSSION}

Most breast abscesses develop as a complication of lactational mastitis. Almost $3 \%$ of lactational mastitis leads to abscess formation ${ }^{10}$. Breast abscess is a common cause of morbidity in women. Breast abscess is relatively less common in developed countries because of improved maternal hygiene, nutrition and standard of living; however it remain a major problem among lactating women in developing countries ${ }^{11}$. The reported incidence of mastitis varies from $10 \%$ to $20 \%$ in the first six months of postpartum $^{12}$. The treatment of breast abscesses ranges from conservative to surgical ${ }^{13}$. Traditionally treatment of breast abscess is incision and drainage which is done under general anesthesia, furthermore it can leads to prolonged healing time, regular dressing, difficulty in breast feeding, and a number of patients are not satisfied with the cosmetic results ${ }^{14}$. Breast abscesses can be treated by repeated needle aspiration with or without ultrasound guidance ${ }^{10,15}$. The necessary symptomatic treatment of breast abscess include analgesia, warm and cold sponge applications, antibiotics and encouraging continued milk flow from the affected breast ${ }^{16}$. The surgeon should tell the patient that antibiotics and pain killers will not affect her baby. The patient should be reassured to continue breastfeeding, and to drink plenty of fluids but some studies support that breast feeding should be suppressed during the treatment. Close monitoring is needed to ensure that the infection resolves ${ }^{17}$.

In current study most patients were between 26 to 30 years of age. The average age of the women in percutaneous aspiration group and drainage group was $27.91 \pm 4.23$ years and $28 \quad \pm 5.04$ years respectively. Kandi AJ et al ${ }^{18}$ reported the maximum number of patients in the age group of 20-24 years in aspirated as well as incised group, however the mean age was $25.37 \pm 6.70$ in aspirated and $27.57 \pm 9.82$ years in incised group respectively which is comparable to current study. Kandi AJ et al observed cessation of breast feeding in $65 \%$ of patients who underwent incision and drainage while it was $2.71 \%$ in patients having aspiration for breast abscess. This finding is indirectly in agreement with the finding of current study where we observed early restoration of breast feeding in $82.2 \%$ among patients of aspiration group. Rate of early restoration of breast feeding was high in percutaneous aspiration group about $80 \%$ than drainage group. The findings were correlated with Christensen et al where most of lactating mothers continued breastfeeding in the treatment period satisfactorily and no milk fistula developed while the study of Chandika $A B$ et al found $66.2 \%$ of lactating patients continued breastfeeding in the treatment period satisfactorily ${ }^{19,7}$. Garg et al reported success rate of $84 \%{ }^{20}$. Elagili $\mathrm{F}$ et al reported success rate of $83.3 \%{ }^{21}$. Chandika $A B$ et al reported that the healing rate of the two groups had no statistically significant difference, both overall and at each visit; this was 
similar with what was found elsewhere ${ }^{7}$. After open surgical drainage of an abscess, suckling is difficult for a few days because of pain and dressing at the operated site, but the mother should be encouraged to feed on the unaffected side to avoid further problems. The manual expression or a breast pump should be used to empty the infected breast. In a study by Saleem S, et al ${ }^{9}$, the outcome of USG needle aspiration was compared with incision drainage of abscess. Sixty patients were included. However, rate of breast feeding cessation was low $(n=4,13 \%)$ in USG percutaneous group as compared to incision drainage $(n=21,70 \%)$. Similarly, satisfaction was $100 \%$ in percutaneous drainage group and $55 \%$ in incision drainage group. In our study we also found early restoration of breast feeding in aspiration group. Chandika $A B$ reported that demographic characteristics, presentation of patients, shape, size and location of the breast abscess had no effect on the rate of healing between the two study groups ${ }^{7}$.

\section{CONCLUSION}

We concluded that percutaneous aspiration of breast abscess is minimally invasive, simple outpatient procedure without the need of general anesthesia with superior cosmetic results, high satisfaction rate. It is very promising, feasible, and efficient alternative method of treatment to conventional incision and drainage in properly selected patients.

\section{REFERENCES}

1. Afshariani $R$, Farhadi $P$, Ghaffarpasand $F$, Roozbeh J. Effectiveness of topical curcumin for treatment of mastitis in breastfeeding women: a randomized, double-blind, placebo-controlled clinical trial. Oman Med J. 2014 Sep;29(5):330-4.

2. Marín M, Arroyo R, Espinosa-Martos I, Fernández L, Rodríguez JM. Identification of Emerging Human Mastitis Pathogens by MALDI-TOF and Assessment of Their Antibiotic Resistance Patterns. Front Microbiol. 2017; 8:1258.

3. Amin AL, Purdy AC, Mattingly JD, Kong $A L$, Termuhlen PM. Benign breast disease. Surg Clin North Am. 2013; 93(2):299-308.

4. Bharat A, Gao F, Aft RL, Gillanders WE, Eberlein TJ, Margenthaler JA . Predictors of primary breast abscesses and Recurrence. World J Surg. 2009; 33(12):2582-86.

5. Kataria K, Srivastava A, Dhar A. Management of lactational mastitis and breast abscesses: review of current knowledge and practice. Ind $\mathrm{J}$ Surg. 2013; 75(6):430-5.

6. Lepori D. Inflammatory breast disease: The radiologist's role. Diagn Interv Imaging. 2015; 96 (10):1045-64.

7. Chandika AB, Gakwaya AM, Kiguli-Malwadde E, Chalya PL. Ultrasound guided needle aspiration versus surgical drainage in the management of breast abscesses: a Ugandan experience. BMC Res Notes. 2012; 5(1):12.

8. Sarhan $\mathrm{HH}$, Ibraheem OM. Percutaneous needle aspiration is a minimally invasive method for a breast abscess. Arch Clin Exp Surg. 2012;1 (2):105-9.

9. Saleem S, Farooq T, Khan N, Shafiq M, Azeem $\mathrm{M}$, Dab RH. Puerperal breast abscesses. Professional Med J. 2008;15(4):431-6.

10. Amir LH, Academy of Breastfeeding Medicine Protocol Committee. ABM clinical protocol\# 4: Mastitis, revised March 2014. Breastfeed Med. 2014; 9(5):239-43.

11. Al-Marzooq TJ, Al-Timimy QA, Mehsen RT. Ultrasound Guided Aspiration versus Drainage under General Anesthesia in Breast Abscesses. Iraqi J Med Sci. 2015; 13(3):235-40.

12. Khanal V, Scott JA, Lee AH, Binns CW. Incidence of mastitis in the neonatal period in a traditional breastfeeding society: results of a cohort study. Breastfeed Med. 2015; 10(10):481-7.

13. Javed MU, Aleem S, Asif SJ, Iqbal J. Breast abscess; comparison of recurrence rate between incision drainage and multiple needle aspiration. Professional Med J. 2017; 24(1):89-94.

14. Lam E, Chan T, Wiseman SM. Breast abscess: evidence based management recommendations. Expert RevAnti Infect Ther. 2014;12(7):753-62.

15. Chamblin C. Lactational Abscess. JOGNN. 2016 Jun 1;45(3):S53.

16. Das P, Nayyar AS. Breast Abscess: A Brief Communication. Int J Med Res Health Sci. 2017; 6(7):42-4.

17. Odiya S, Mathur R, Arora S. Comparative study of conventional incision and drainage versus percutaneous placement of suction drain: changing trend of breast abscess management. Int Surg J. 2016; 3(3):1580-4.

18. Kandi AJ, Gite VA, Varudkar AS. A comparative study of outcomes in management of breast abscess by ultrasound guided needle aspiration against incision and drainage. Int Med J. 2014; 1 (10):655-9.

19. Christensen AF, Al-Suliman N, Nielsen KR, Vejborg I, Severinsen N, Christensen $H$, et al. Ultrasound-guided drainage of breast abscesses: results in 151 patients. $\mathrm{Br} \mathrm{J}$ Radiol 2005; 78(927): 186-88. 
20. Garg P, Rathee SK, Lal A. ultrasonically guided percutaneous drainage of breast abscess. J Indian Med Assoc. 1997; 95(11):584-5. breast abscess under ultrasound guidance: outcome obtained and factors affecting success. Asian J Surg. 2007;30(1):40-4.

21. Elagili F, Adbullah N, Fong L, Pei T. Aspiration of



AUTHOR AFFILIATION:

Dr. Noor Hussain

Postgraduate Trainee, Department of Surgery

Jinnah Postgraduate Medical Center

(JPMC) Karachi, Sindh-Pakistan.

Dr. Imran Khan (Corresponding Author) Assistant Professor, Department of Surgery JPMC Karachi, Sindh-Pakistan.

Email: dr.imranjpmc@gmail.com

Dr. Tanweer Ahmed

Assistant Professor, Department of Surgery

JPMC Karachi, Sindh-Pakistan.

Dr. Sughra Parveen

Professor, Department of Surgery

JPMC Karachi, Sindh-Pakistan.

Dr. Mariam Malik

Postgraduate Trainee, Department of Surgery

JPMC Karachi, Sindh-Pakistan.

Dr. Muhammad Iqbal Khan

Associate Professor, Department of Surgery

JPMC Karachi, Sindh-Pakistan. 